IOS Press

\title{
Interview with Arthur Kennickell ${ }^{1}$
}

\author{
Katherine M. Condon \\ Statistical Journal of IAOS \\ E-mail:kcondoniaos@gmail.com
}

\section{Introduction}

Arthur Kennickell has been involved in economic measurement at the Federal Reserve for over three decades. He was previously interviewed in this journal back in $2013 .^{2}$ The focus of that interview was on his three-decades of work at the Board of Governors of the Federal Reserve System (Federal Reserve), and particularly with regard to his work leading the Survey of Consumer Finances (SCF). The SCF is a critical source of information on the U.S. national economy and economic livelihood of American households.

Commenting on one of the important aspects of Arthur's leadership at the Federal Reserve, the previous interview noted

Arthur's approach to leadership is predicated on absorbing the wisdom of others - be it staff, interviewers or respondents - and focusing everyone's energy on the highest data quality possible. He has utilized the power of listening to overcome a tremendous number of methodological and operational problems. The way in which the survey has tackled the challenges of change and complexity provides a case study of how Arthur collects and synthesizes the information necessary to confront difficult survey challenges. ${ }^{3}$

\footnotetext{
${ }^{1}$ The views and opinions expressed in the conversation are those of the interviewee and do not necessarily reflect the policy or position of the Statistical Journal of the International Association for Official Statistics nor IOS Press. Further, the views and opinions expressed by the interviewee in this conversation may not necessarily reflect the policy or position of the Federal Reserve Board or its staff.

${ }^{2}$ Rae, M. and DeHaan, R. 2013. "Arthur Kennickell, Federal Reserve Board, USA." Statistical Journal of the IAOS. 29: 119125. http://content.iospress.com/download/statistical-journal-of-theiaos/sji00763?id=statistical-journal-of-the-iaos\%2Fsji00763.

${ }^{3}$ Ibid.
}

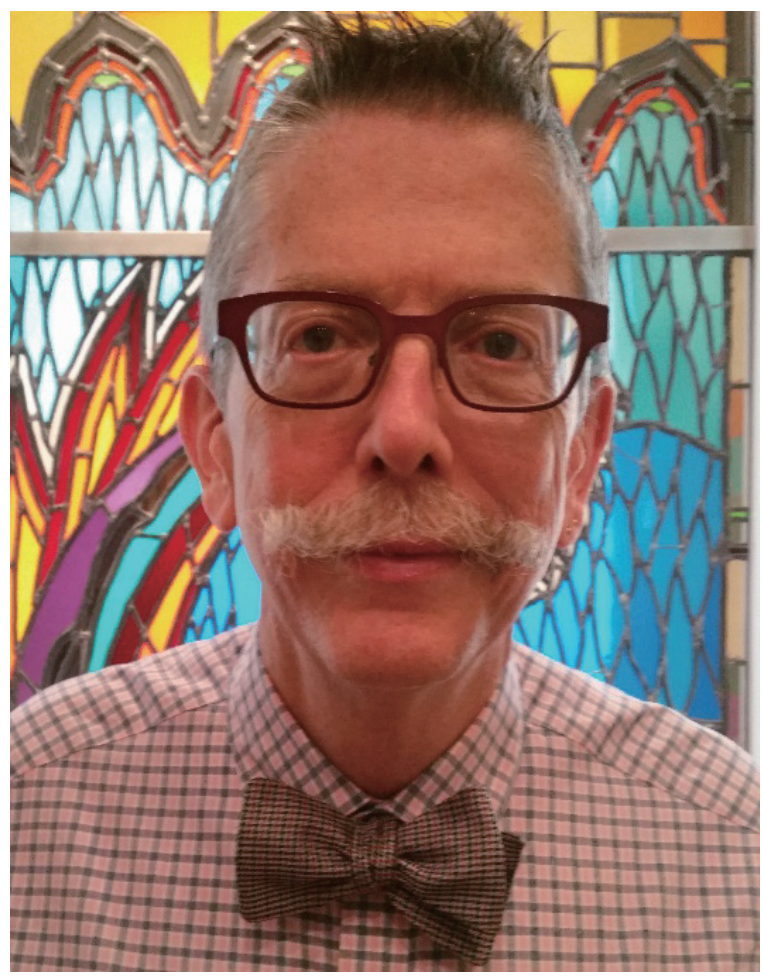

Arthur Kennickell - September 2016

Thus, in this current interview, we wanted to step back and get a sense of the fuller picture of how Arthur Kennickell came to the field of economics and statistics. His work is the focus of this special issue, which has the theme "Constant Focus: Engaging to Measure Wealth." The in-person interview with Arthur Kennickell was done by Katherine Condon on September 30, 2016.

Arthur received his BA from University of Chicago in General Studies with primary concentrations in 
physics and fine arts. ${ }^{4}$ After finishing an MA there, he left academia to become a self-employed artist. However, after seven years he returned to academia to study economics at University of Pennsylvania (Philadelphia, PA) with a specialization in Finance and Public Finance. His dissertation was entitled "An Investigation of Life Cycle Saving Behavior in the United States." He completed his dissertation in 1984 and went to work for the Federal Reserve, where he has served in many roles throughout the three decades.

\section{INTERVIEWER: Thank you so much for allowing us to interview you. I am interested in how you came to your double concentration in physics and the fine arts and then turned to economics and finance?}

I started at the University of Chicago in the physics department and just in the physics department at the time. But I was also an artist. It was reasonably common at the time to have that connection between art and science. During the time around the Kent State problems, ${ }^{5}$ something happened that changed my path. There were not a lot of demonstrations on the Chicago campus. It was a very serious place and students were very serious - and they still are. We went to the library to have fun. At one point during this period a faculty member was denied tenure. The prevailing thought at the time was that she was denied due to her leftwing sympathies. This decision crystalized some other grudges students had about the perceived abuses of the university. The result was a sit-in at the Administration Building. ${ }^{6}$ I didn't participate in this because I was

\footnotetext{
${ }^{4} \mathrm{I}$ am a daughter and a grand-daughter of two physicists and a niece of another physicist, but turned my interests to demography, statistics and economics in my undergraduate and graduate studies. So, I wanted to also learn what made Arthur choose physics and fine arts as an undergraduate studies and then turn to economics in his graduate studies.

${ }^{5}$ The incident Arthur is referring to is variously known as "Kent State Massacre", "Kent State Shooting" or "the May 4 Massacre." It happened on May 4, 1970 at Kent State University. Unarmed students were demonstrating against the Cambodian Campaign recently announced by President Nixon. The outcome was that four students were killed outright and nine others were wounded when the Ohio National Guard fired 67 rounds over a period of 13 seconds on May 4, 1970. For more information, see: https://en.wikipedia.org/ wiki/Kent_State_shootings.

${ }^{6}$ This event happened in 1969. It was reported that more than 400 students participated in occupying the Administration Building for two weeks. The occupation ended when the popular professor turned down a one-year reappointment. The student participants suffered
}

fairly skeptical about arguments on both sides on the tenure denial issue. Generally, I try to keep an open mind and see the evidence on both sides of an argument. However, I knew some people who participated in the sit-in. At one point, I went in to take food to my friends. Well, the night after I saw them, a raid was staged by the faculty. Among the faculty participants on the raid were members of the physics faculty. What was most striking to me about what these physics faculty saw and reported is that they simply did not see any of the male physics students, but they did see the women physics students who were there. All those women physics students ${ }^{7}$ were reported to the administration. That was really a stomach-turning moment.

After that I started to look very closely at the people who were my teachers and thinking about some of the other things that they had done. I thought carefully about spending the rest of my life working with those people and I realized it was not something for me. So, I knew that I needed to figure out what else I could do. The University of Chicago had (and I hope still has) some very interesting inter-disciplinary programs - some of them were way out there. One was called the Committee on General Studies in Humanities. You could put together joint majors, which we didn't typically have. I wound up getting my degree with concentrations in physics and fine arts, and there was a bit of music thrown in there too. Physics and fine arts have some deep connections: both try to see things in an abstract way and probe the nature of reality.

After I graduated I became a self-employed artist. However, one of the things that I came to realize was that I was not very good at selling myself - I really didn't like it at all. I probably should have tried to get better at it then. I felt that this was going to pose a big problem for me if I wanted to continue all on my own as an artist. In 1978 I was in living in Washington and I happened to meet a lot of people who had de-

further consequences; 42 students were expelled and 81 were suspended. For more information about the University of Chicago, see https://en.wikipedia.org/wiki/University_of_Chicago.

${ }^{7}$ Arthur noted a little later that there were maybe about a halfdozen or so women physics students in his entering cohort at University of Chicago. In my own research of PhD's granted in the field of physics during the early 1900s, I had seen only a few women being granted a PhD in physics. The field was basically a male bastion. Arthur also noted that he had done some work in this area using time series data from the National Science Foundation for economics. He stated that there were more women in the field of economics than one would expect to see before World War II and then it goes to virtually zero in the 1950s and it wasn't until the 1970s that one starts to see an up-tick and now it is more substantial. 
grees in economics. I saw that with an economics degree you could do a lot of different things. It isn't as if one could only be, say, an economic forecaster. It is possible to use an economics background to work on a wide range of things. This flexibility was appealing. Most of the people I met who were economists were really interesting people - not all of them, but a good number of them. [We had a chuckle at that]. After that I started to think seriously about applying to graduate school in economics. I was interested in a more empirical approach. I got into the University of Pennsylvania (Penn) - along with some other places. I liked Philadelphia, so I chose Penn. It turned out to be a good choice for me, because my advisor was Albert Ando. ${ }^{8} \mathrm{He}$ was especially famous for his work with Franco Modigliani on the Life Cycle Hypothesis but he had many other interesting aspects that made us a good match. ${ }^{9,10}$

Very early in grad school I had an experience that shaped my path there. One of my teachers, Robert Schiller, assigned a homework problem that led me to think hard about the nature of measurement and in particular the value of micro-data. The problem was posed as what appeared on the surface to be a simple problem in aggregation over the behavior of a group of households. But because of some inherent nonlinearity in the structure of the underlying behaviors, aggregation in any straightforward way was not possible. It made me think that it was only by looking at behavior starting at a relatively atomic level that I would be able to understand anything at a higher level.

Later, when I was writing my dissertation under Albert Ando, I knew I wanted to use micro-data to understand "saving behavior" and wealth accumulation at the household level. There were some serious impediments, such as the computers were not as fast as they are now and the methodology for handling data was not

\footnotetext{
8“Albert Ando was born in Tokyo, Japan in 1929 and came to the United States after World War II. He received his B.S. in economics from the University of Seattle in 1951, his M.A. in economics from St. Louis University in 1953, and an M.S. in economics in 1956 and a Ph.D. in mathematical economics in 1959 from Carnegie Institute of Technology (now Carnegie Mellon University), where he was a student of Herbert Simon. Dr. Ando came to Penn in 1963 as an associate professor of economics and finance and became professor of economics and finance in 1967. He held this position until his death [in 2002]." (Source: Obituary http://www.upenn.edu/almanac/v49/n06/deaths.html). For more information about Albert Ando, also see: https://en.wikipedia.org/ wiki/Albert_Ando.

${ }^{9}$ For more information about Franco Modigliano see: https://en. wikipedia.org/wiki/Franco_Modigliani.

${ }^{10}$ For more information on the Life Cycle Hypothesis ( $\left.\mathrm{LCH}\right)$, see: https://en.wikipedia.org/wiki/Life-cycle_hypothesis.
}

as well understood then. I managed to find a number of sources of micro-data. But as I began to look closely at the data, I began to wonder why I should be able to draw any inference from these data about something happening in the world. Albert was very supportive of me and my scrupulousness. He had an unusual range of interests and we got along really well almost all the time. (Well, he was my advisor).

He encouraged my interest in measurement. He also had some interest in measurement of his own. I wound up giving myself a course in survey statistics, sampling theory, and all of things I thought then that I needed to know to understand why I might be able to make those inferences. That was a good experience and a really unusual experience in graduate school for an economist. This work was very important for me as a foundation. It wound up leading me to things I would not have imagined at the time.

\section{INTERVIEWER: Was there a particular person who shaped you into the person you are today?}

The most important person in my growing up was my double maternal Great Aunt Ina Walker, who lived in Waycross, Georgia. I met her briefly a number of times when I was very young. When I was 6-years old, I reached an age where I could visit people and it was a tradition of going to visit my Aunt Ina and her husband Red. So, I was sent there.

I have to say that I was not exactly an unhappy child up to that point, but I was very conscious that I did not fit in. I didn't feel I was like anyone else in my family or any of the other people that I came in contact with growing up in Savannah. It was a really terrible feeling for a small child and nobody seemed to notice. Maybe people would notice now, but they didn't then. Maybe some of it was being a very young gay person in a world where such things were made invisible.

My family was a bit isolated too - my mother was an only child and her mother raised her alone. The only other person available to me in that family was my Aunt Ina. My father had a living father, brothers and a sister but for whatever reason we did not have meaningful contact with them and I never understood why. It was during this first visit to Aunt Ina that I felt like I had truly come home. I discovered that my aunt and I had, in a sense, the same mind. It was a really big deal for me to realize at that age that there are different kinds of minds, not just superficialities of personality. There are people in the world who think in very 
different ways. That was the most transformative thing that happened in my young life. I have long felt that experience saved me.

So, I think it was my Aunt Ina who was the "particular person" who shaped me most into the person I am today. But there are so many other people in my life since I left home who have touched me deeply. I can't possibly mention all of them, and I would not want to slight anyone by giving a partial list. But I can say that for my work in measurement, the most important people for me have been my dissertation advisor, Fritz Scheuren my great friend for 30 years, and the people I have met who are close to the pulse of actual measurement. In an introductory essay I have written for this issue, I say some more about these people.

\section{INTERVIEWER: You entered the University of Chicago as an undergraduate. Was there a particular reason for this choice in college? What was it like to do your undergraduate studies during this particularly dramatic period of time in the American history?}

I grew up in Savannah [Georgia]. One summer before my senior year in high school, I went to a summer science program sponsored by the State of Georgia. It was a surprising and a little intimidating to me to realize how much better trained people from some other areas - particularly Atlanta - were. Those of us who came from other parts of the state were sometimes looked down upon. We were doing the best we could within the confines of what we had seen. This experience motivated me to learn more.

One of the days during this summer program was devoted to seeing representatives of universities. At that point I had assumed I would go to Georgia Tech and get a physics degree there, since it was not so far away from home. But something happened to change my plans. The man from Georgia Tech didn't know very much about the physics program and he made it sound like it was not a very serious place to be. For good or bad, I have tended to be a pretty serious person my whole life, so this was a big turn-off. Then, there was Mrs. Patrick Niger - I don't know what her real name was, but that's how she introduced herself. She was representing the University of Chicago. She was so inspiring to me. I applied for "early decision" and got in, so I never applied anywhere else. ${ }^{11}$ While all the important things she said turned out to be true, she did leave out some things. For example, when I was in college, Chicago was viewed on polls of students as less congenial than West Point - and it was. It was an extremely serious place, but it was inspiring. Going there was one of the best decisions that I made, because it was all about critical thinking, skepticism, and being able to see and understand perspectives in everything.

[This brought about a little diversion in our conversation about what the value of a college education should be - whether it be narrowly defined as "taskoriented" production line or a broader perspective of thinking beyond the current production line thinking but being able to think beyond what is in the here and now economy. Arthur made the point that "task oriented education is one of the riskiest types of education" as it "pigeon-holes individuals into a particular job in the economy."]

When I left Savannah to go to Chicago - Lester Maddox was governor of Georgia - it was a very bad time to be in the South. When I was leaving to go to Chicago, I remember thinking how upsetting it was that I was leaving the people I cared about and the things there that I cared about most. But at the same time, it was so clear that almost everything precious to me was stained and corrupted with something evil racism. I had a view that in getting away to Chicago, somehow everything would be so much better. But it wasn't and that was a big disappointment - I discovered that it was actually worse in many ways. We still have a long way to go before things will be truly fair.

\section{INTERVIEWER: Has the field of economics and finance changed since you received your education? If no, what has sustained it? If yes, in what ways has it changed?}

One of the specialty fields that I did in grad school was finance. I did it because I thought it was interesting - not because I especially wanted to go into finance, but because of the astonishing degree of continuing evolution in that area. Some of that evolution turned out later to be good and some of it was not so

\footnotetext{
11 "Early decision ... is a common policy used in college admissions in the United States for admitting freshmen to undergraduate programs. It is used to indicate to the university or college that the candidate considers that institution to be his or her top choice." Source: https://en.wikipedia.org/wiki/Early_decision.
} 
good. I hope later in this conversation I can tell you about some work that I have been doing the last 5 or 6 years in the area of finance. It has been interesting to come back into the field again - doing new research and seeing just how measurement and basic philosophical constructs like "identity" are so important there.

One current development I see as deeply important for economics is the recognition that behavioral economics has something to offer. Economics isn't just a utility maximization thing - while that paradigm is very useful as a frame of reference, it doesn't describe all of reality. People are not computers - we all have emotions and laziness that can blind us; we are usually dealing with partial information; we can't see every side of an issue all at the same time in decisionmaking. The neo-classical model is a helpful point of reference, but it is only one line across a vast space of possibility. Behavioral economics allows us to recognize other things that come into play with decisionmaking. Perhaps some of the things we learn will help people make better decisions - for example, as in some of the work Annmaria Lusardi ${ }^{12}$ has done on financial literacy. How do we prepare people to make big decisions, for example on retirement, without being taken advantage of? Perhaps we can make some progress with behavioral economics. I always remember what John Maynard Keynes said about economics, he said, [or as Arthur paraphrased it] - if we economists work really hard, maybe someday we can be as useful as dentists. ${ }^{13}$

[We chuckled at that one]

Great ideas often start from broad and sophisticated thinkers, such as Adam Smith and others in the Scottish Enlightenment who gave important foundations for economics. These brilliant people were trying to understand their economic environment and the decisions underlying it. Unfortunately, there is a tendency in many areas, not just economics, to drive to a point of seeming rigor that can become a rigid parody of reality.

\footnotetext{
${ }^{12}$ For more information on Annamaria Lusardi, see https://en. wikipedia.org/wiki/Annamaria_Lusardi.

${ }^{13}$ I was able to find the actual quote "... do not let us overestimate the importance of the economic problem, or sacrifice to its supposed necessities other matters of greater and more permanent significance. It should be a matter for specialists-like dentistry. If economists could manage to get themselves thought of as humble competent people, on a level with dentists, that would be splendid!" SOURCE: Keynes, J. M. 1930 "Economic Possibilities for our Grandchildren." Essays in Persuasion. New York: W.W. Norton \& Co., 1963. pp: 358-373. http://www.managementaccounting.info/ wp-content/uploads/2015/09/Economic-Possibilities-for-OurGrandchildren.pdf.
}

There was an economist (and he might have also been a statistician) - I think his name was William Stanley Jevons ${ }^{14}$ and he has a marvelous quote - "A despotic calm is usually the triumph of error." 15 Sometimes a little turbulence can help us advance.

[We left it there - to move on to Arthur's professional career accomplishments.]

INTERVIEWER: Your work life (post-college) has been at the Federal Reserve, which was discussed at length in the 2013 interview. For those who haven't read that interview, could you summarize your accomplishments and what you see as your greatest accomplishment during your over 30-years at the Federal Reserve?

That's really hard. I did try to think about that before this interview. I worked for almost 3 decades on the Survey of Consumer Finance (SCF). ${ }^{16}$

That is work I am really happy to have been involved with, although maybe less happy with the way it wound up for me and the views I value. I have a point of view about measurement and the way that a healthy system of measurement should progress. Unfortunately, that point of view wasn't shared by all. I can accept that. As I see it, measurement is a very serious discipline that requires constant focus to accommodate to the complexities of the surrounding environment through time. The possibility of failure is always at hand, though it may occur so gradually that it is not seen in time. Stable formal models and systems are necessary for coping with immediate problems - the "emergency room" paradigm. However, time should also be devoted to relentless and transparent examination of weak points. This is not a problem relevant just for surveys and other formal measurement - this is life. In any case, that work was a good thing to have done for many reasons, not least for the development of so much important data for research. I wish the people doing that work now well.

\footnotetext{
${ }^{14}$ For more information on the life of William Stanley Jevons, see: https://en.wikipedia.org/wiki/William_Stanley_Jevons. For more quotes attributed to William Stanley Jevons, see: https://en. wikiquote.org/wiki/William_Stanley_Jevons.

${ }^{15}$ I was able to find the quote - it is in Chapter 8 of Jevons' work titled, The Theory of Political Economy (1871). See http://la.utexas. edu/users/hcleaver/368/368JevonsNoxious.html.

${ }^{16}$ Rae and DeHaan (2013) piece focused exclusively on this survey. Following is summary description of the SCF from their article.
} 


\begin{abstract}
The Survey of Consumer Finance [SCF] is a critical resource in understanding some of the most fundamental economic questions of our day: from who owns what - to how we own what we own. A sign of the SCFarís impact is its reach: from popular publications, such as articles on income inequality, consumer awareness of their debt holdings and the indebtedness of younger Americans - to scholarly work comparing the assets of uninsured households to the deductibles of health plans with HSAs and the distribution of household investments. The survey asks respondents detailed questions about their financial holdings and liabilities, allowing researchers to compare income, stockholdings, home ownership and debt across key demographic groups. The key work product of the survey is the bulletin, which reports the newest findings and crosstabs for key variables in the study.

SOURCE: Rae and DeHaan, 2013. op. cit.
\end{abstract}

I also want to bring up two other things that I have contributed to and that I am happier about because they are more current and I see life in them. One of them is work that I have done with the European Central Bank (ECB). ${ }^{17}$ I got a call back in 2006 from Reint Gropp who was then at the ECB. He said that that they were thinking about conducting a wealth survey, which became the Household Finance and Consumption Survey. ${ }^{18}$ They asked if I would mind coming to spend a couple of days with them in a workshop. It turned out to be a difficult time for me to travel. But they were so nice to me and so persistent, that I really felt that I had to be there to share what I could. I am very glad I said yes. I found people who were very receptive to thinking about measurement at a very basic level and up.

They had a difficult problem in that they wanted to have a survey across all the various euro zone countries - at the time there were about 15 different countries. The proposed survey would be executed at the local level, but centrally coordinated. So it was important to build as much common infrastructure as possible and a common point of view, while also recognizing the inevitable diversity in the implementation. That constraint turns out to be both a problem and a strength. It's a problem for obvious reasons. We would like to find the right way to achieve our objectives, using the exact same measurement process everywhere. However, there is virtue in having different points of view and operating by consensus. Thus, no one can say, "You must do this." There was lots of discussion and things have moved forward in a better way be-

\footnotetext{
${ }^{17}$ https://www.ecb.europa.eu/ecb/orga/html/index.en.html.

${ }^{18}$ https://www.ecb.europa.eu/pub/economic-research/researchnetworks/html/researcher_hfcn.en.html.
}

cause there has been so much discussion. There is also the local flexibility to deal with institutional structures that can differ strongly across the member countries. I find the work still to be going in a good and healthy direction. My outsider status has given me scope to help bring people together sometimes. For whatever part I've managed to play in the success of their wealth survey, I am grateful that I could be there to help them. I'm grateful to them for calling me and letting me be involved, as well as grateful to the Federal Reserve Board for letting me go to work on this.

The second item that I am especially happy about is that for the past 5 or 6 years, I've been working on something called the Global Legal Entity Identifier (LEI) System. ${ }^{19}$ The system still isn't broadly known at this point outside some areas of finance or regulation. Coming out of the financial crisis (2008) there was a recognition that at critical moments, it often was very hard to link essential data on market participants when that information was needed. The data were often messy and entities were identified in many different ways. Much time was spent printing things out and trying to figure out who was who. It still goes on today.

Even more complicated is the problem of understanding the actions of complex organizations - not just the sometimes thousands of individual legal entities of which they may be composed. Take the classic case of Lehman Brothers. When the decision was made to let Lehman Brothers go down, no one in the regulatory world had a map of the whole corporate structure of Lehman Brothers. Many of the actual parts of Lehman Brothers didn't have "Lehman Brothers" as a part of their names. People did the best they could to put this all together, but it really wasn't known how it would all fall out.

There was a gap in our understanding of the structure and we needed to do something about it. There was a G-20 initiative to develop a solution. They asked the Financial Stability Board (FSB) to lead a group to investigate this issue. I was fortunate enough to be asked to participate in this group. The FSB initiative brought together a broad group of participants from many institutions globally to work together to develop a framework to support more effective identification. We had help generously volunteered by academics, market practitioners, lawyers, standards experts and a variety of others. We developed a specific technical and governance framework, so that there could be a glob-

\footnotetext{
${ }^{19}$ For more information, see http://www.sifma.org/issues/ operations-and-technology/legal-entity-identifier/overview/.
} 


Why do we need a global LEI?
The establishment of a global LEI system will be a significant
achievement in responding to the vulnerabilities of the global fi-
nancial system and will provide meaningful long-term benefits
for both the public and private sectors. When Lehman Brothers
collapsed in 2008, financial regulators and private sector man-
agers were unable to assess quickly the extent of market par-
ticipantsaŕ exposure to Lehman or to explore quickly and fully
how the vast network of market participants were connected to
one another. Subsequently, the financial crisis exposed the depth
of the problem of identifying financial connections and under-
scored the long-standing need for a global system to identify
and link data, which will enable financial regulators and firms
to better understand the true nature of risk exposures across the
financial system.
When industry adopts the global LEI, data reported both ex-
ternally to supervisors and internally for risk management pur-
poses will be more reliable. The global LEI will enhance the
ability of regulators to monitor and analyze threats to finan-
cial stability and the ability of risk managers to evaluate their
companiesaŕ risks. It will facilitate improved micro-prudential
and macroprudential risk analysis, supervision, and regulation;
reduce cost for industry in collecting, cleaning, and aggregat-
ing data, and in reporting data to government regulators; reduce
private firmsaŕ operational risks and improve their internal risk
management; and enhance industryaŕs market discipline.
SOURCE: Department of Treasury. 2012. Frequently Asked
Questions: Global Legal Entity Identifier (LEI). https://www.
treasury.gov/initiatives/wsr/ofr/Documents/LEI_FAQs_August
2012_FINAL.pdf.

ally distributed federated system of entity registration with common quality standards and an oversight function from a regulatory body to ensure it works right. We created a Swiss foundation to manage the operational core of the system.

We have over 70 different members of the regulatory body, as well as several observer members. There has been a very positive effort from all sides to work together. Many people consider it a model for the way that international work should be conducted. Because the goal of the work moves close to some areas of great complexity, it would have been easy to be bogged down in time-consuming and ultimately destructive arguments. This did not happen. We worked together to accommodate differences, while upholding the needs of our home institutions. We constructed a system that could unfold globally in a way that has so far made it resilient.

\section{INTERVIEWER: How is this going?}

The system has been implemented and it is growing. About a half-million entities have been registered so far - of course, there are many millions left to go in or- der for the LEI to be the universal identifier for entities. If you look at the OTC derivatives space, you will see that there is virtually 100-percent coverage of counterparties there. It is a mandatory regulatory requirement for such trades here in the U.S. and in Europe, as well as some other areas. For the moment at least, it is moving faster in other markets in Europe now than in the U.S. It has the high-level political backing of the G-20 through the endorsement of the initial recommendations and the charter of the regulatory group. It also has the subsequent endorsement by all the member authorities. That's the strength behind it. It isn't a treaty, but it comes out of a consensus and a common framework. This generates confidence in the marketplace that it will not disappear.

The big step of evolution proceeding in the system now is adding a second dimension of identification: the organizational structures that tie groups of entities together. This will be implemented starting in 2017. To me this work has moved rather fast. But perhaps not everyone would agree. While it would have been nice if it had happened faster, that it is happening at all is very important. Such fundamental change, especially on a global basis, is difficult and even threatening to some people.

All aspects of this work have been very interesting to me. I have had the great pleasure of serving as the chair of the technical committee of the regulatory group. That has allowed me to engage in work on all the underpinnings of the system. I enjoy complex systems. This is a very good one - and it is very useful!

\section{INTERVIEWER: Overall, what are some of the challenges you see facing you and also for current statistician/economists working in government settings?}

For the field, specifically for measurement, as that is what I have the most knowledge about, and that's where my heart is, I think we need to accept the fact that the world has fundamentally changed. Data are being generated all the time by processes that are not directly under our control. For example, some of these data are being generated by mechanical processes, private and government administrative functions, and choice-driven interactions. Such data often appear to be timely, free and certainly abundant. They come on top of what we create as statisticians in a more holistically structured way in surveys and other such structured information collections. But many things are 
happening to undermine that structured model - such as non-response and non-sampling error, which are generally getting worse or more expensive to address. We are trying to cope with the collision of these data sources. In doing so, it is highly important to do all we can to maintain a transparent and objective process, while serving the needs within the constraints of what is technically and fiscally achievable.

Although we have a great deal of experience in some aspect of blending data sources, such as in national income accounts, there are also entirely new questions. For example, would it be possible to take a survey with a usual annual frequency, move to a quinquennial basis and use times-series data generated by another process to extrapolate the survey estimates between waves? Are the times series stationary enough? Are there questions of future access to the time series? Do we understand their properties of the resulting estimates well enough? If we don't, what can we do to minimize the risks of potentially faulty estimates? Official statisticians and scholars in many places are working hard to address these and related problems. These are very interesting questions for a young person in measurement, or even an old person like me. Especially for a young person writing a dissertation, this would be a great area to work in.

\section{INTERVIEWER: Do you have any words of wisdom for students preparing for working in the world of official statistics?}

Yes, I do. In preparing for this interview I thought about this and I wrote down some hopes for words of wisdom so I wouldn't forget them.

First, it is good to be prepared for the fact that a lot of other people don't really understand why one should care deeply about measurement. So, one should not go into the world of official statistics with eyes closed. There will be some serious obstacles, including institutional cultures, and particularly so in institutions that are dominated by one profession. For example, at the Federal Reserve the culture - especially in the research divisions - is heavily economist-centric. Economists tend to have a certain focus, and it is a very useful focus for a lot of things close to the mission of my institution. But the risk of a dominant discipline without serious checks and balances is that views from other disciplines can be not so much suppressed as either not noticed or taken as irrelevant. This seems to me often a problem for measurement. As we all move to a more evidence-based standard for policies, understanding the deeper nature of supporting information becomes ever more important. I think institutions in general need to be more sensitive to this and figure out ways to get people to pay attention. Or perhaps they need better salesmen than me to hammer in this point!

For a young person, it is good to start out with a view that you may not figure out all that you want to do right at the beginning. I have a favorite quote from William Blake from a book that he wrote entitled The Marriage of Heaven and Hell ${ }^{20}$ in a section called the "Proverbs of Hell". The line is something to the effect that 'a straight road gets you someplace in a hurry, but crooked roads without improvements are roads of genius.' 21

There is another Blake proverb maybe relevant here: "If others had not been foolish, we should be so." This is a really important one, because so often people take the view that everything that has gone before and then been superseded by something else is just wrong and should be ignored. Instead, we should be grateful. Most often, there is a lot to be learned by looking more closely. Generally, professions aren't totally stupid and at any given time they are trying to do the right thing with what they can see. If they had agreed on a certain structure of the world in whatever the discipline may be, there is value in understanding why it was that way and how it transitioned to the newer view of the world. Otherwise, one just ends up more deeply planted in the current rut. One must understand the potential fragility of a point of view. This is another thing that I would encourage a young person to be especially aware of.

Finally, it would not be complete without telling them to be brave. Do the right thing and try to make a difference. Be humble, but don't be too humble. This is a mistake made most often by people who aren't apt at pushing themselves forward. Sometimes the more aggressive people have very good ideas and are simply highly motivated to express them. But, sometimes they push themselves forward because they have ego-

\footnotetext{
${ }^{20}$ For more information see: https://en.wikipedia.org/wiki/The_ Marriage_of_Heaven_and_Hell.

21 "Improvement makes straight roads, but the crooked roads without Improvement are roads of Genius." From William Blake's The Marriage of Heaven and Hell. "The Proverbs of Hell." This is a good model, I think, for someone starting out in a career - to accept that you may need to keep winding around. Keep your eyes open. Be skeptical and look at things carefully. If you do, you will find something much richer than you would otherwise. You can find the things that motivate you, if you follow that path and keep your eyes open. You will see doors opening that you didn't know initially were there and would never have seen otherwise.
} 
deficiencies that they need to fill at the expense of other people and the things that might otherwise have been achieved. By holding back, the more reticent people allow unnecessary selection bias to occur. Let your work state things with appropriate skepticism. Be humble about what your work can say, but don't be humble about the objectives that you are trying to achieve. See yourself as a positive instrument.

INTERVIEWER: We thank you so very much for talking with us. 